\title{
Review
}

\section{Nicotine and inflammatory neurological disorders}

\author{
Wen-Hua PIAO ${ }^{1,2, *}$, Denise CAMPAGNOLO ${ }^{1}$, Carlos DAYAO ${ }^{1}$, Ronald J LUKAS ${ }^{1}$, Jie WU ${ }^{1}$, Fu-Dong SHI ${ }^{1, *}$ \\ ${ }^{1}$ Barrow Neurological Institute, St Joseph's Hospital and Medical Center, Phoenix, AZ 85013, USA; ${ }^{2}$ Department of Clinical Laboratory, Ningxia People's \\ Hospital, Yinchuan 750021, China
}

\begin{abstract}
Cigarette smoke is a major health risk factor which significantly increases the incidence of diseases including lung cancer and respiratory infections. However, there is increasing evidence that smokers have a lower incidence of some inflammatory and neurodegenerative diseases. Nicotine is the main immunosuppressive constituent of cigarette smoke, which inhibits both the innate and adaptive immune responses. Unlike cigarette smoke, nicotine is not yet considered to be a carcinogen and may, in fact, have therapeutic potential as a neuroprotective and anti-inflammatory agent. This review provides a synopsis summarizing the effects of nicotine on the immune system and its (nicotine) influences on various neurological diseases.
\end{abstract}

Keywords: nicotine; cigarette smoke; immune system

Acta Pharmacologica Sinica (2009) 30: 715-722; doi: 10.1038/aps.2009.67; published online 18 May 2009

\section{Introduction}

Cigarette smoke is the leading cause of preventable diseases worldwide and, in the USA alone, smoking causes approximately 400000 deaths annually ${ }^{[1,2]}$. Smoking is associated with an increased incidence of acute respiratory infections ${ }^{[3]}$, periodontitis ${ }^{[4]}$, bacterial meningitis ${ }^{[5]}$, rheumatoid arthritis ${ }^{[6]}$, Crohn's disease ${ }^{[7]}$, systemic lupus erythematosus $^{[8]}$, atherosclerosis ${ }^{[9]}$, chronic obstructive pulmonary diseases ${ }^{[10]}$, lung cancer ${ }^{[11]}$ and coronary heart disease $^{[12]}$. While increasing data indicate that smoking might decrease the incidence and/or severity of several diseases, including ulcerative colitis ${ }^{[13,14]}$, Parkinson's disease $(\mathrm{PD})^{[15-18]}$, some forms of Alzheimer's disease $(\mathrm{AD})^{[19-21]}$, hypersensitivity pneumonitis (HP ${ }^{[22]}$ and type I diabetes ${ }^{[23]}$; nicotine also protects the kidneys from renal ischemia/reperfusion injury ${ }^{[24]}$.

A multitude of studies suggest that nicotine, a psychoactive component of tobacco products, acts in a similar fashion as the naturally occurring neurotransmitter, acetylcholine, on nicotinic acetylcholine receptors (nAChRs) found in many organ systems and has profound immunological effects ${ }^{[25,26]}$.

* Correspondence to Dr Fu-Dong SHI or Dr Wen-Hua PIAO.

E-mail Fu-Dong.Shi@chw.edu or wenhuapiao@hotmail.com

Received 2009-03-22 Accepted 2009-04-14
During ontogeny, nicotine exposure can modulate $\mathrm{T}$ cell and $\mathrm{B}$ cell development and activation ${ }^{[27]}$. Nicotine exposure also suppresses the $\mathrm{T}$ cell response and alters the differentiation, phenotype and functions of antigen-presenting cells (APCs), including dendritic cells ${ }^{[28,29]}$ and macrophages ${ }^{[30]}$. Exposure to nicotine and/or related agents appears to dampen inflammatory responses and reduce mortality in a mouse model of sepsis ${ }^{[31]}$ and to protect against induction of type 1 diabetes in mice ${ }^{[23]}$. In addition, cigarette smoke inhalation produces sustained suppression of humoral autoimmunity in a murine model of systemic lupus erythematosus (SLE) ${ }^{[32]}$. Moreover, several epidemiological studies reveal a strong inverse correlation between smoking and human autoimmune responses manifesting as SLE and ulcerative colitis ${ }^{[32,33]}$. By contrast, other studies suggest that smoking behavior in humans might exacerbate multiple sclerosis (MS) and Crohn's disease ${ }^{[34-39]}$. Our recent results show that nicotine exposure significantly delays and attenuates inflammatory and autoimmune responses to myelin antigens in the mouse experimental autoimmune encephalomyelitis (EAE) model ${ }^{[40]}$. These apparently conflicting observations suggest that the impact of nicotine on immune responses in vivo is complex, being potentially influenced by drug dosage and duration of exposure, the specific organ systems involved in the immune response, the stage and type of disease and by the level of involvement of autoimmune and inflammatory mechanisms. 


\section{Nicotine and immunity}

It has long been contemplated that many of the health consequences of chronic cigarette smoking may reflect its adverse effects on the immune system ${ }^{[41]}$. Nicotine is a major psychoactive compound in tobacco product. Accumulating evidence suggests that nicotine, a drug that stimulates nicotinic acetylcholine receptors, has profound immunological effects $^{[41]}$.

Nicotine effects on the immune system in vitro There is some evidence that nicotine exposure in vitro can produce changes in immunocytes by reportedly affecting the lyses of target cells ${ }^{[42,43]}$, decreasing PHA-induced proliferation in human peripheral blood lymphocytes ${ }^{[44]}$, inducing suppressor cell activity in human $\mathrm{T}$ lymphocytes and exhibiting a biphasic effect on the mitogenic responses of peripheral blood lymphocytes ${ }^{[45]}$. Aside from its direct effect on peripheral $\mathrm{T}$ cells, nicotine also influences $\mathrm{T}$ cell development ${ }^{[27,46]}$ and alters the expression of certain surface proteins on $\mathrm{T}$ cells ${ }^{[47]}$. During the primary immune response, exposure of nicotine to T-cells results in altered IL-2, IL-10, and IFN- $\gamma$ expression in mice ${ }^{[48]}$. Furthermore, nicotine inhibits the IL-12 and IL-18 production of ICAM-1, B7.2 and CD40 on monocytes through the up-regulation of cyclooxygenase (COX-2) expression ${ }^{[49]}$. Pretreatment with low-dose nicotine causes inhibition of the production of IL-12, IFN- $\gamma$, prostaglandin E2, macrophage inflammatory protein (MIP)-1 and TNF- $\alpha$. In addition, nicotine suppresses the phosphorylation of I- $\kappa B$ thereby inhibiting the transcriptional activity of NF- $\mathrm{kB}$ and suppressing HMGB1 release $^{[31,49-51]}$. These suppressive effects of nicotine occur at the transcriptional level and are mediated through $\alpha 7 \mathrm{nAChR}$.

While macrophages initiate many inflammatory and innate immune functions, dendritic cells (DCs) are the principal antigen-presenting cells. In previous years, several reports documented the biological effect of nicotine on DCs and macrophages ${ }^{[29,52-56]}$. Nicotine has been reported to decrease levels of proinflammatory cytokines and reduce the ability of T-cell priming ${ }^{[54,57]}$, but has also been described to enhance the costimulatory molecular expression in DCs and facilitate T-cell priming ${ }^{[53]}$. In a recent study, it has also been reported that nicotine could up-regulate expression of nicotinic acetylcholine receptors, costimulatory molecules (such as CD80, CD86), CD40, CD11b, and chemokine receptor, $\mathrm{CCR} 7{ }^{[28,29]}$. Nicotine could also enhance the endocytotic ability of imDCs in addition to possibly promoting imDC dependent CTL priming and IL-12 secretion in vitro ${ }^{[28,29,58]}$.

Nicotine effects on the immune system in vivo Increasing evidence has shown that nicotine exerts its effects on the immune system in vivo. Nicotine affects both humoral and cell-mediated branches of the immune system ${ }^{[2,40,59-61]}$ and produces an altered immune response that is characterized by a decrease in inflammation ${ }^{[62]}$, a decreased antibody response and a reduction in $\mathrm{T}$ cell-receptor-mediated signaling ${ }^{[60]}$. These effects probably stem from the direct impact that nicotine acts on $\mathrm{T}$ lymphocytes. It has been reported that treatment of $\mathrm{T}$ lymphocytes with nicotine provides signals that mimic TCR-mediated cell activation signals, thus leading to partial activation of $\mathrm{T}$ cells, resulting in $\operatorname{anergy}^{[60,63,64]}$. Chronic administration of nicotine causes $\mathrm{T}$ cell anergy, which are primarily mediated via the activation of the hypothalamus-pituitary-adrenal axis ${ }^{[65]}$. Nicotine exposure has been associated with the induction of regulatory $\mathrm{T}$ cells $^{[45]}$. Nicotine also affects B lymphocyte development and controls B lymphocyte survival via nicotinic acetylcholine receptors ${ }^{[66-69]}$.

Nicotine treatment of a mouse alveolar macrophage cell line (expressing $\alpha 4$ and $\beta 2$, but not $\alpha 7 \mathrm{nAChR}$ subunits) results in enhanced intracellular replication of Legionella pneumophilia ${ }^{[70]}$. Further, the production of the inflammatory cytokines IL- 6 , TNF- $\alpha$, and IL-12 are down-regulated in these cells. In our EAE model, we also observed similar results ${ }^{[40]}$. Nicotine-induced inhibition of macrophage function may protect against inflammatory lung processes, such as HP, by decreasing the number of alveolar macrophages in the lungs of experimental animals and decreasing inflammatory cytokine production ${ }^{[22]}$. Furthermore, chronic nicotine exposure results in a reduction of lung $S$-adenosylmethionine (AdoMet), which is required for growth of Pneumocystitis carinii $^{[71]}$.

\section{Spectrum of neurological diseases}

Nicotine and Parkinson's disease (PD) PD is a debilitating neurodegenerative movement disorder occurring in $\sim 1 \%$ of the population over the age of 55 . It is the second most common neurodegenerative disease and is characterized by relatively selective damage to dopaminergic nigrostriatal neurons that leads to motor deficits including tremor, rigidity, bradykinesia and postural instability ${ }^{[72,73]}$. Although the entire pathogenesis of PD is still unclear, both environmental and genetic factors contribute to neurodegeneration.

Epidemiological studies have shown an association of smoking with a lower occurrence of PD (Table 1). While several studies were conflicting in regard to worsening of motor performance ${ }^{[74-77]}$ and the effects of smoking being dose dependent ${ }^{[78,79]}$, this negative association between smoking and PD is reproducible, dose related and not a 
Table 1. Summary of the effectiveness of nicotine in the neurological diseases patients.

\begin{tabular}{cll}
\hline Disease & Clinical effect & References \\
\hline \multirow{2}{*}{ PD } & Protect & {$[15-18]$} \\
& No effect & {$[74-77]$} \\
$\mathrm{AD}$ & Protect & {$[19-21]$} \\
& No effect & {$[111,112]$} \\
$\mathrm{MS}$ & High risk & {$[35,37-39]$} \\
\hline
\end{tabular}

result of selective mortality. Although the component in cigarette smoke that confers this apparent neruoprotective action remains to be identified, numerous studies using experimental animal models suggest that nicotine protects against PD through receptor-mediated and non-receptormediated pathways as well (Table 2). Nicotine activates the striatal or mesolimbic dopaminergic system ${ }^{[80]}$, and protects against glutamate-induced neurotoxicity in striatal, cortical and mesencephalic neurons, as well as nigrostriatal degeneration in MPTP-treated animals ${ }^{[18,81,82]}$. Nicotine protects against $\mathrm{PD}$ by non-receptor-mediated and receptormediated pathways. Nicotine could suppress the formation of toxin by directly influencing enzyme activities, such as monoamine oxidases $(\mathrm{MAO})^{[83]}$. Nicotine might also modulate the members of the cytochrome P450 (CYP) fam-

Table 2. Summary of neuroprotective effects of nicotine in animal models.

\begin{tabular}{|c|c|c|c|}
\hline Model & $\begin{array}{l}\text { Clinical } \\
\text { effect }\end{array}$ & Mechanisms & References \\
\hline PD & Protect & $\begin{array}{l}\text { Non-receptor-mediated: } \\
\text { MAO } \\
\text { cytochrome P450 (CYP) family } \\
\text { mitochondrial complex I activity } \\
\text { antioxidant }\end{array}$ & $\begin{array}{l}{[83]} \\
{[84-87]} \\
{[88-90]} \\
{[83,89]}\end{array}$ \\
\hline & & $\begin{array}{l}\text { Receptor-mediated: } \\
\alpha 4 \beta 2 \\
\alpha 7 \\
\alpha 6 \alpha 4 \beta 2 \\
\alpha 6 \beta 2\end{array}$ & $\begin{array}{l}{[15,95,97]} \\
{[16,51,98]} \\
{[95]} \\
{[15,95,99]}\end{array}$ \\
\hline $\mathrm{AD}$ & Protect & $\begin{array}{l}\text { Reduce } A \beta \text { accumulation and } \\
\text { aggregation via } \alpha 7 \mathrm{nAchR} \\
\text { Inhibit NO production } \\
\text { Prevent MAPK, NF- } \mathrm{B} \text {, and c-Myc } \\
\text { pathways via } \alpha 7 \mathrm{nAchR}\end{array}$ & $\begin{array}{l}{[113,114]} \\
{[114]} \\
{[114]} \\
{[114]}\end{array}$ \\
\hline
\end{tabular}

EAE Protect ily $^{[84-87]}$. Furthermore, nicotine could act by modulating mitochondrial complex I activity to preserve mitochondrial function and consequently reduce neuronal damage ${ }^{[88-90]}$, or through a direct chemical action as an antioxidant ${ }^{[83,89]}$. Nicotinic effects could be mediated by stimulating different nAChR subtypes, such as $\alpha 4 \beta 2, \alpha 7, \alpha 6 \alpha 4 \beta 2, \alpha 6 \beta 2$, etc ${ }^{[51,91-99]}$. Numerous signaling pathways are altered in response to $\mathrm{nACh}$ receptor activation, including presynaptic pathways involved in control of neurotransmitter release (dopamine, ACh, GABA, and glutamate $)^{[100]}$ and postsynaptic pathways involved in apoptosis (phospholipase $\mathrm{C}$, arachidonic acid, reactive oxygen species, neuronal nitric oxide synthase, and cGMP) and necrosis (phospholipase C, protein kinase C, MAPK, ERK, and Bcl2) ${ }^{[101-104]}$, immune modulation (IL-1, IL-6, and TNF $\alpha)^{[16,105]}$ and neurotrophic factor production (brain derived neurotrophic factor, fibroblast growth factor $2)^{[106,107]}$. Activation of these pathways might subsequently lead to neuroprotection through inhibition of toxin-induced apoptosis, and increased expression of neurotrophic factors, which are crucial for neuronal maintenance, survival and regeneration.

Nicotine and Alzheimer's disease $\mathrm{AD}$ is the most common neurodegenerative disorder that is characterized by impairment of learning and memory. It affects $\sim 2 \%$ of the population in industrialized countries. Loss of recent memory is one of the earliest clinical manifestations, but as the disease progresses, patients suffer additional memory losses and experience other cognitive impairments as well. Ultimately, $\mathrm{AD}$ patients deteriorate and eventually are no longer able to maintain their own personal independence ${ }^{[108]}$. Neuropathological and neurochemical hallmarks of this disease include the presence of extracellular neuritic plaques composed of $\beta$-amyloid peptide (A $\beta)$, neutofibrillary tangles composed of tau protein and a loss of cholinergic neurons of the basal forebrain ${ }^{[109,110]}$.

One way for humans to modulate their own cholinergic system is through smoking tobacco. It is fairly well-established that smoking cigarettes can have a protective effect against PD mentioned previously. However, the situation is less clear for AD. Several epidemiological studies have explored the relationship between cigarette smoking and $\mathrm{AD}$, with many of these studies reaching contradictory conclusions (Table 1). These epidemiological studies have been, broadly speaking, either case-control or cohort studies. In general, the case-control studies show that smoking is associated with a decreased risk for developing $\mathrm{AD}$. In contrast, cohort studies tend to show a higher risk of developing $\mathrm{AD}$ in smokers compared to non-smokers ${ }^{[111,112]}$.

Nicotine protects against $\mathrm{AD}$ through $\alpha 7 \mathrm{nAChR}$ - 
mediated and non-receptor-mediated pathways as well (Table 2). Nicotine reduces accumulation of $A \beta$ in the cortex and hippocampus of amyloid precursor protein (V7171) transgenic mice via $a 7 \mathrm{nAChR}^{[113]}$. Nicotine prevents activation of NF- $\mathrm{kB}$ and $\mathrm{c}-\mathrm{Myc}$ by inhibiting the activation of MAPKs, resulting in the activation of inducible NOS and the down-regulated production of NO. Further investigation shows that nicotine decreases $A \beta$ via the activation of $\alpha 7$ nAChRs through MAPK, NF-kB, and c-Myc pathways ${ }^{[114]}$. Nicotine could also inhibit apoptosis and cell cycle progression in this mouse line ${ }^{[114]}$.

Nicotine and multiple sclerosis MS is an immunemediated, chronic inflammatory autoimmune disease of the central nervous system (CNS) that is characterized by inflammation, demyelination and axonal damage. Its onset usually starts between 20 and 40 years of age. The prevalence of MS is estimated to be around 400000 persons in the Unites States and 2 million people worldwide ${ }^{[115,116]}$. MS leads to substantial disability through deficits of sensation, motor, autonomic and neurocognitive function. Current theories concerning the pathogenesis of MS involve genetic and environmental factors as well as immune dysregulation.

Epidemiological studies have shown an association of smoking with a higher occurrence of $\mathrm{MS}^{[35,37,39]}$, while our results show that nicotine exposure significantly delays and attenuates inflammatory and autoimmune responses to myelin antigens in the mouse experimental autoimmune encephalomyelitis (EAE) model ${ }^{[40]}$. This occurs whether nicotine treatment begins prior to, at the time of, or after immunization with myelin antigens to induce EAE. Moreover, nicotine exposure also suppresses disease development on adoptive transfer of autoimmune T cells. First, we demonstrated that the expansion of MOG-reactive $\mathrm{T}$ cells from the spleen in nicotine-treated mice was significantly dampened. In these animals, MOG-reactive Th cells produced less IFN- $\gamma$ and IL- 2 than cells from PBS-treated controls, whereas the production of IL-10, and particularly TGF- $\beta$, was augmented. A marginal, but not significant, reduction of IL-17 was observed in mice received nicotine. Our observation is somewhat surprising given the augmentation of TGF- $\beta$ in nicotine exposed mice. Nicotine also did not appear to induce apoptosis in autoreactive $\mathrm{T}$ cells. This outcome invites the prediction that the immunological effects induced by nicotine may have contributed to the decreased $\mathrm{T}$ cell proliferation and altered cytokine profile. We also observed that, although the absolute numbers of $\mathrm{CD} 4^{+} \mathrm{CD} 25^{+}$regulatory $\mathrm{T}$ cells were not dramatically altered by nicotine exposure, expression of FoxP3 was significantly upregulated. These regulatory $\mathrm{T}$ cells with enhanced FoxP3 expression may contribute to the suppression of $\mathrm{T}$ effector/ autoreative cells. Furthermore, we found that nicotine significantly reduced levels of MHC class II, CD80, and CD86 expression on peripheral $\mathrm{CD} 11 \mathrm{c}^{+}$and $\mathrm{CD} 11 \mathrm{~b}^{+}$cells. Notably, these changes were more dramatic for $\mathrm{CD} 11 \mathrm{~b}^{+}$cells. It is likely that the altered APC phenotype in nicotine-treated animals may, at least in part, reduce the encephalitogenic capacity of MOG-reactive T cells in the EAE model.

In the CNS, in sharp contrast with control EAE mice, nicotine-treated animals had relatively few cellular infiltrates in CNS. Further, flow cytometry analysis of the cellular infiltrates showed that a significant reduction of $\mathrm{CD} 4^{+}, \mathrm{CD}^{+}$, $\mathrm{CD} 19^{+}, \mathrm{CD} 11 \mathrm{c}^{+}, \mathrm{CD} 11 \mathrm{~b}^{+}$, and $\mathrm{CD} 11 \mathrm{~b}^{+} \mathrm{CD} 45^{+}$cell populations; and the reductions in $\mathrm{CD} 19^{+} \mathrm{B}$ cells and $\mathrm{CD} 11 \mathrm{c}^{+}$ dendritic cells seem to reflect diminished migration into the CNS from the periphery. It is presently unclear whether the reduction of $\mathrm{CD} 4^{+}$and $\mathrm{CD} 8^{+}$cells in the CNS stems from reduced influx from the periphery, impaired expansion in the CNS after migration, or both. Whatever the mechanism may be, it is clear that there is significantly reduced expression of antigen presentation machinery by resident or infiltrating $\mathrm{CD} 11 \mathrm{c}^{+}$and $\mathrm{CD} 11 \mathrm{~b}^{+}$cells.

There are several possibilities as to how nicotine attenuates the disease even after EAE has been initiated after concurrence of CNS symptoms (Table 2). Nicotine may inhibit myelin-reactive $\mathrm{T}$ cell determinant spreading when $\mathrm{T}$ cells migrating from the periphery encounter CNS antigens.

\section{Conclusion}

Nicotine, the psychoactive component of tobacco smoke, has profound immunological effects. Nicotine has been shown to alter immune responses by decreasing inflammation, decreasing the antibody-forming cell response of splenocytes, decreasing proliferation of peripheral blood mononuclear cells, regulating lymphocytes, macrophages, DC, and affecting the secretion of cytokines of lymphocytes. Nicotine is an agonist at $\mathrm{nAChRs,} \mathrm{which} \mathrm{causes} \mathrm{it} \mathrm{to} \mathrm{interfere}$ with immune responses in a receptor-mediated manner. Nicotine is being considered as an anti-inflammatory agent for the treatment of some diseases such as $\mathrm{AD}, \mathrm{PD}$, and Crohn's disease. The effect of nicotine on immune cells, however, is incompletely characterized and controversial. Differences in gender, animal species, age, and disease manifestations may alter the effects of nicotine. The dosage, routes of administration and time may also greatly influence its effects on immunity. Further studies are needed to elucidate the effects of nicotine on the immune system and its effects on various kinds of diseases, including MS. 
Epidemiological studies have identified a negative correlation between smoking and the development of neurodegenerative disorders such as $\mathrm{PD}$, and in some studies, $\mathrm{AD}$. These findings have been attributed to the ability of nicotine to act as a neuroprotective agent. Despite the compelling evidence that nicotine is neuroprotective, it is clear that nicotine can be toxic under some circumstances. The balance between nicotine neuroprotection and toxicity depends on dose, developmental stage and regimen of administration. Therefore, a full understanding of the molecular and cellular effects of nicotine on signaling pathways relevant to neuronal survival is critical for informed drug discovery of nicotinic compounds to combat human neurodegeneration.

\section{Acknowledgements}

This work was supported by Barrow Neurological Foundation.

We thank Alain SIMARD and Paul WHITEAKER for discussions.

\section{Abbreviations}

$\mathrm{AD}$, Alzheimer's disease; APCs, antigen-presenting cells; DC, dendritic cell; EAE, experimental autoimmune encephalomyelitis model; MS, multiple sclerosis; nAChRs, nicotinic acetylcholine receptors; PBL, peripheral blood lymphocytes; PD, Parkinson's disease; SLE, systemic lupus erythematosus.

\section{References}

1 Boyle AH, Waters HF. COPD: focus on prevention: recommendations of the National Lung Health Education Program. Chronic obstructive pulmonary disease. Heart Lung 2000; 29: 446-9.

2 Johnson JD, Houchens DP, Kluwe WM, Craig DK, Fisher GL. Effects of mainstream and environmental tobacco smoke on the immune system in animals and humans: a review. Crit Rev Toxicol 1990; 20: 369-95.

3 Nishikawa M. Cigarette smoke-induced acute airway impairment. Nihon Kokyuki Gakkai Zasshi 2000; 38: 347-53.

4 Obeid P, Bercy P. Effects of smoking on periodontal health: a review. Adv Ther 2000; 17: 230-7.

5 Gold R. Epidemiology of bacterial meningitis. Infect Dis Clin North Am 1999; 13: 515-25.

6 Klareskog L, Padyukov L, Alfredsson L. Smoking as a trigger for inflammatory rheumatic diseases. Curr Opin Rheumatol 2007; 19: 49-54.

7 Rhodes J, Thomas GA. Smoking: good or bad for inflammatory bowel disease? Gastroenterology 1994; 106: 807-10.

8 Costenbader KH, Kim DJ, Peerzada J, Lockman S, Nobles-Knight $\mathrm{D}$, Petri M, et al. Cigarette smoking and the risk of systemic lupus erythematosus: a meta-analysis. Arthritis Rheum 2004; 50: 84957.

9 Sobczak AJ. The effects of tobacco smoke on the homocysteine level - a risk factor of atherosclerosis. Addict Biol 2003; 8: 147-58.

10 Sethi JM, Rochester CL. Smoking and chronic obstructive pulmonary disease. Clin Chest Med 2000; 21: 67-86.

11 Ozlu T, Bulbul Y. Smoking and lung cancer. Tuberk Toraks 2005; 53:200-9.

12 Lindell KO, Reinke LF. Nursing strategies for smoking cessation. Heart Lung 1999; 28: 295-302.

13 Birtwistle J. The role of cigarettes and nicotine in the onset and treatment of ulcerative colitis. Postgrad Med J 1996; 72: 714-8.

14 Birrenbach T, Bocker U. Inflammatory bowel disease and smoking: a review of epidemiology, pathophysiology, and therapeutic implications. Inflamm Bowel Dis 2004; 10: 848-59.

15 Quik M, Bordia T, O'Leary K. Nicotinic receptors as CNS targets for Parkinson's disease. Biochem Pharmacol 2007; 74: 1224-34.

16 Park HJ, Lee PH, Ahn YW, Choi YJ, Lee G, Lee DY, et al. Neuroprotective effect of nicotine on dopaminergic neurons by anti-inflammatory action. Eur J Neurosci 2007; 26: 79-89.

17 Quik M, Parameswaran N, McCallum SE, Bordia T, Bao S, McCormack A, et al. Chronic oral nicotine treatment protects against striatal degeneration in MPTP-treated primates. J Neurochem 2006; 98: 1866-75.

18 Quik M. Smoking, nicotine and Parkinson's disease. Trends Neurosci 2004; 27: 561-68.

19 Sabbagh MN, Lukas RJ, Sparks DL, Reid RT. The nicotinic acetylcholine receptor, smoking, and Alzheimer's disease. J Alzheimers Dis 2002; 4: 317-25.

20 Fratiglioni L, Wang HX. Smoking and Parkinson's and Alzheimer's disease: review of the epidemiological studies. Behav Brain Res 2000; 113: 117-20.

21 Newhouse PA, Potter A, Kelton M, Corwin J. Nicotinic treatment of Alzheimer's disease. Biol Psychiatry 2001; 49: 268-78.

22 Blanchet MR, Israel-Assayag E, Cormier Y. Inhibitory effect of nicotine on experimental hypersensitivity pneumonitis in vivo and in vitro. Am J Respir Crit Care Med 2004; 169: 903-9.

23 Mabley JG, Pacher P, Southan GJ, Salzman AL, Szabo C. Nicotine reduces the incidence of type I diabetes in mice. J Pharmacol Exp Ther 2002; 300: 876-81.

24 Sadis C, Teske G, Stokman G, Kubjak C, Claessen N, Moore F, et al. Nicotine protects kidney from renal ischemia/reperfusion injury through the cholinergic anti-inflammatory pathway. PLoS ONE 2007; 2: e469.

25 McAllister-Sistilli CG, Caggiula AR, Knopf S, Rose CA, Miller AL, Donny EC. The effects of nicotine on the immune system. Psychoneuroendocrinology 1998; 23: 175-87.

26 Sopori M. Effects of cigarette smoke on the immune system. Nat Rev Immunol 2002; 2: 372-7.

27 Middlebrook AJ, Martina C, Chang Y, Lukas RJ, DeLuca D. Effects of nicotine exposure on $\mathrm{T}$ cell development in fetal thymus organ culture: arrest of T cell maturation. J Immunol 2002; 169: 2915-24.

28 Nouri-Shirazi M, Tinajero R, Guinet E. Nicotine alters the biological activities of developing mouse bone marrow-derived dendritic cells (DCs). Immunol Lett 2007; 109: 155-64.

29 Guinet E, Yoshida K, Nouri-Shirazi M. Nicotinic environment 
affects the differentiation and functional maturation of monocytes derived dendritic cells (DCs). Immunol Lett 2004; 95: 45-55.

30 Floto RA, Smith KG. The vagus nerve, macrophages, and nicotine. Lancet 2003; 361: 1069-70.

31 Wang H, Liao H, Ochani M, Justiniani M, Lin X, Yang L, et al. Cholinergic agonists inhibit HMGB1 release and improve survival in experimental sepsis. Nat Med 2004; 10: 1216-21.

32 Rubin RL, Hermanson TM, Bedrick EJ, McDonald JD, Burchiel $\mathrm{SW}$, Reed MD, et al. Effect of cigarette smoke on autoimmunity in murine and human systemic lupus erythematosus. Toxicol Sci 2005; 87: 86-96.

33 Jani N, Regueiro MD. Medical therapy for ulcerative colitis. Gastroenterol Clin North Am 2002; 31: 147-66.

34 Emre M, de Decker C. Effects of cigarette smoking on motor functions in patients with multiple sclerosis. Arch Neurol 1992; 49: 1243-7.

35 Friend KB, Mernoff ST, Block P, Reeve G. Smoking rates and smoking cessation among individuals with multiple sclerosis. Disabil Rehabil 2006; 28: 1135-41.

36 Johnson GJ, Cosnes J, Mansfield JC. Review article: smoking cessation as primary therapy to modify the course of Crohn's disease. Aliment Pharmacol Ther 2005; 21: 921-31.

37 Hawkes $\mathrm{CH}$. Smoking is a risk factor for multiple sclerosis: a metanalysis. Mult Scler 2007; 13: 610-5.

38 Hernan MA, Olek MJ, Ascherio A. Cigarette smoking and incidence of multiple sclerosis. Am J Epidemiol 2001; 154: 6974.

39 Koch M, van Harten A, Uyttenboogaart M, De Keyser J. Cigarette smoking and progression in multiple sclerosis. Neurology 2007; 69: $1515-20$.

40 Shi FD, Piao WH, Kuo YP, Campagnolo DI, Vollmer TL, Lukas RJ. Nicotinic attenuation of central nervous system inflammation and autoimmunity. J Immunol 2009; 182: 1730-9.

41 Sopori ML, Kozak W. Immunomodulatory effects of cigarette smoke. J Neuroimmunol 1998; 83: 148-56.

42 Hamada M, Hendrick JP, Ryan GR, Kuroiwa M, Higashi H, Tanaka M, et al. Nicotine regulates DARPP-32 (dopamine- and cAMP-regulated phosphoprotein of $32 \mathrm{kDa}$ ) phosphorylation at multiple sites in neostriatal neurons. J Pharmacol Exp Ther 2005; 315: 872-8.

43 Neumann S, Razen M, Habermehl P, Meyer CU, Zepp F, Kirkpatrick CJ, et al. The non-neuronal cholinergic system in peripheral blood cells: effects of nicotinic and muscarinic receptor antagonists on phagocytosis, respiratory burst and migration. Life Sci 2007; 80: 2361-4.

44 Neher GH. Nicotine-induced depression of lymphocyte growth. Toxicol Appl Pharmacol 1974; 27: 253-8.

45 Menard L, Rola-Pleszczynski M. Nicotine induces T-suppressor cells: modulation by the nicotinic antagonist $\mathrm{D}$-tubocurarine and myasthenic serum. Clin Immunol Immunopathol 1987; 44: $107-13$.

46 Hallquist N, Hakki A, Wecker L, Friedman H, Pross S. Differential effects of nicotine and aging on splenocyte proliferation and the production of Th1- versus Th2-type cytokines. Proc Soc Exp Biol Med 2000; 224: 141-6.

47 Zhang S, Petro TM. The effect of nicotine on murine CD4 T cell responses. Int J Immunopharmacol 1996; 18: 467-78.

48 Petro TM, Schwartzbach SD, Zhang S. Smokeless tobacco and nicotine bring about excessive cytokine responses of murine memory T-cells. Int J Immunopharmacol 1999; 21: 103-14.

49 Takahashi HK, Iwagaki H, Hamano R, Yoshino T, Tanaka N, Nishibori M. Effect of nicotine on IL-18-initiated immune response in human monocytes. J Leukoc Biol 2006; 80: 1388-94.

50 Takahashi HK, Iwagaki H, Hamano R, Yoshino T, Tanaka N, Nishibori M. alpha7 Nicotinic acetylcholine receptor stimulation inhibits lipopolysaccharide-induced interleukin-18 and -12 production in monocytes. J Pharmacol Sci 2006; 102: 143-6.

51 Yoshikawa H, Kurokawa M, Ozaki N, Nara K, Atou K, Takada E, et al. Nicotine inhibits the production of proinflammatory mediators in human monocytes by suppression of I-kappaB phosphorylation and nuclear factor-kappaB transcriptional activity through nicotinic acetylcholine receptor alpha7. Clin Exp Immunol 2006; 146: 116-23.

52 Vassallo R, Tamada K, Lau JS, Kroening PR, Chen, L. Cigarette smoke extract suppresses human dendritic cell function leading to preferential induction of Th-2 priming. J Immunol 2005; 175: 2684-91.

53 Aicher A, Heeschen C, Mohaupt M, Cooke JP, Zeiher AM, Dimmeler S. Nicotine strongly activates dendritic cellmediated adaptive immunity: potential role for progression of atherosclerotic lesions. Circulation 2003; 107: 604-11.

54 Nouri-Shirazi M, Guinet E. Evidence for the immunosuppressive role of nicotine on human dendritic cell functions. Immunology 2003; 109: 365-73.

55 Wang H, Yu M, Ochani M, Amella CA, Tanovic M, Susarla S, et al. Nicotinic acetylcholine receptor alpha7 subunit is an essential regulator of inflammation. Nature 2003; 421: 384-8.

56 Matsubayashi H, Inoue A, Amano T, Seki T, Nakata Y, Sasa M, et al. Involvement of alpha7- and alpha4beta2-type postsynaptic nicotinic acetylcholine receptors in nicotine-induced excitation of dopaminergic neurons in the substantia nigra: a patch clamp and single-cell PCR study using acutely dissociated nigral neurons. Brain Res Mol Brain Res 2004; 129: 1-7.

57 Hogg N. Nicotine has suppressive effects on dendritic cell function. Immunology 2003; 109: 329-30.

58 Gao FG, Wan da F, Gu JR. Ex vivo nicotine stimulation augments the efficacy of therapeutic bone marrow-derived dendritic cell vaccination. Clin Cancer Res 2007; 13: 3706-12.

59 Kalra R, Singh SP, Savage SM, Finch GL, Sopori ML. Effects of cigarette smoke on immune response: chronic exposure to cigarette smoke impairs antigen-mediated signaling in $\mathrm{T}$ cells and depletes $\mathrm{IP}_{3}$-sensitive $\mathrm{Ca}^{2+}$ stores. J Pharmacol Exp Ther 2000; 293: 166-71.

60 Sopori ML, Kozak W, Savage SM, Geng Y, Soszynski D, Kluger MJ, et al. Effect of nicotine on the immune system: possible regulation of immune responses by central and peripheral mechanisms. Psychoneuroendocrinology 1998; 23: 189-204.

61 Basta PV, Basham KB, Ross WP, Brust ME, Navarro HA. Gestational nicotine exposure alone or in combination with ethanol down-modulates offspring immune function. Int $\mathrm{J}$ Immunopharmacol 2000; 22: 159-69.

62 Kalra R, Singh SP, Pena-Philippides JC, Langley RJ, RazaniBoroujerdi S, Sopori ML. Immunosuppressive and anti-inflammatory effects of nicotine administered by patch in an animal model. Clin Diagn Lab Immunol 2004; 11: 563-8.

63 Evavold BD, Sloan-Lancaster J, Allen PM. Tickling the TCR: 
selective T-cell functions stimulated by altered peptide ligands. Immunol Today 1993; 14: 602-9.

64 Sloan-Lancaster J, Allen PM. Significance of T-cell stimulation by altered peptide ligands in $\mathrm{T}$ cell biology. Curr Opin Immunol 1995; 7: 103-9.

65 Singh SP, Kalra R, Puttfarcken P, Kozak A, Tesfaigzi J, Sopori ML. Acute and chronic nicotine exposures modulate the immune system through different pathways. Toxicol Appl Pharmacol 2000; 164: 65-72.

66 Skok M, Grailhe R, Agenes F, Changeux JP. The role of nicotinic acetylcholine receptors in lymphocyte development. J Neuroimmunol 2006; 171: 86-98.

67 Skok M, Grailhe R, Changeux JP. Nicotinic receptors regulate B lymphocyte activation and immune response. Eur J Pharmacol 2005; 517: 246-51.

68 Skok MV, Grailhe R, Agenes F, Changeux JP. The role of nicotinic receptors in B-lymphocyte development and activation. Life Sci 2007; 80: 2334-6.

69 Fujii YX, Fujigaya H, Moriwaki Y, Misawa H, Kasahara T, Grando SA, et al. Enhanced serum antigen-specific IgG1 and proinflammatory cytokine production in nicotinic acetylcholine receptor alpha7 subunit gene knockout mice. J Neuroimmunol 2007; 189: 69-74.

70 Matta SG, Balfour DJ, Benowitz NL, Boyd RT, Buccafusco JJ, Caggiula AR, et al. Guidelines on nicotine dose selection for in vivo research. Psychopharmacology (Berl) 2007; 190: 269-319.

71 Shivji M, Burger S, Moncada CA, Clarkson AB Jr, Merali S. Effect of nicotine on lung $\mathrm{S}$-adenosylmethionine and development of Pneumocystis pneumonia. J Biol Chem 2005; 280: 15219-28.

72 Bezard E, Brotchie JM, Gross CE. Pathophysiology of levodopainduced dyskinesia: potential for new therapies. Nat Rev Neurosci 2001; 2: 577-88.

73 Olanow CW, Tatton WG. Etiology and pathogenesis of Parkinson's disease. Annu Rev Neurosci 1999; 22: 123-44.

74 Ebersbach G, Stock M, Muller J, Wenning G, Wissel J, Poewe W. Worsening of motor performance in patients with Parkinson's disease following transdermal nicotine administration. Mov Disord 1999; 14: 1011-3.

75 Clemens P, Baron JA, Coffey D, Reeves A. The short-term effect of nicotine chewing gum in patients with Parkinson's disease. Psychopharmacology (Berl) 1995; 117: 253-6.

76 Vieregge A, Sieberer M, Jacobs H, Hagenah JM, Vieregge P. Transdermal nicotine in PD: a randomized, double-blind, placebo-controlled study. Neurology 2001; 57: 1032-5.

77 Lemay S, Chouinard S, Blanchet P, Masson H, Soland V, Beuter $A$, et al. Lack of efficacy of a nicotine transdermal treatment on motor and cognitive deficits in Parkinson's disease. Prog Neuropsychopharmacol Biol Psychiatry 2004; 28: 31-9.

78 Gorell JM, Rybicki BA, Johnson CC, Peterson EL. Smoking and Parkinson's disease: a dose-response relationship. Neurology 1999; 52: 115-9.

79 Hernan MA, Takkouche B, Caamano-Isorna F, Gestal-Otero JJ. A meta-analysis of coffee drinking, cigarette smoking, and the risk of Parkinson's disease. Ann Neurol 2002; 52: 276-84.

80 Janhunen S, Ahtee L. Differential nicotinic regulation of the nigrostriatal and mesolimbic dopaminergic pathways: implications for drug development. Neurosci Biobehav Rev 2007; 31: 287314.
81 Pidoplichko VI, DeBiasi M, Williams JT, Dani JA. Nicotine activates and desensitizes midbrain dopamine neurons. Nature 1997; 390: 401-4.

82 Maggio R, Riva M, Vaglini F, Fornai F, Molteni R, Armogida M, et al. Nicotine prevents experimental parkinsonism in rodents and induces striatal increase of neurotrophic factors. J Neurochem 1998; 71: 2439-46.

83 Soto-Otero R, Mendez-Alvarez E, Hermida-Ameijeiras A, LopezReal AM, Labandeira-Garcia JL. Effects of (-)-nicotine and (-)-cotinine on 6-hydroxydopamine-induced oxidative stress and neurotoxicity: relevance for Parkinson's disease. Biochem Pharmacol 2002; 64: 125-35.

84 Howard LA, Miksys S, Hoffmann E, Mash D, Tyndale RF. Brain CYP2E1 is induced by nicotine and ethanol in rat and is higher in smokers and alcoholics. Br J Pharmacol 2003; 138: 1376-86.

85 Miksys S, Lerman C, Shields PG, Mash DC, Tyndale RF. Smoking, alcoholism and genetic polymorphisms alter CYP2B6 levels in human brain. Neuropharmacology 2003; 45: 122-32.

86 Miksys S, Tyndale RF. Nicotine induces brain CYP enzymes: relevance to Parkinson's disease. J Neural Transm Suppl 2006; (70): 177-80.

87 Mann A, Miksys S, Lee A, Mash DC, Tyndale RF. Induction of the drug metabolizing enzyme CYP2D in monkey brain by chronic nicotine treatment. Neuropharmacology 2008; 55: 1147-55.

88 Cormier A, Morin C, Zini R, Tillement JP, Lagrue G. Nicotine protects rat brain mitochondria against experimental injuries. Neuropharmacology 2003; 44: 642-52.

89 Newman MB, Arendash GW, Shytle RD, Bickford PC, Tighe T, Sanberg PR. Nicotine's oxidative and antioxidant properties in CNS. Life Sci 2002; 71: 2807-20.

90 Xie YX, Bezard E, Zhao BL. Investigating the receptorindependent neuroprotective mechanisms of nicotine in mitochondria. J Biol Chem 2005; 280: 32405-12.

91 Quik M, Kulak JM. Nicotine and nicotinic receptors; relevance to Parkinson's disease. Neurotoxicology 2002; 23: 581-94.

92 Picciotto MR, Zoli M. Neuroprotection via nAChRs: the role of nAChRs in neurodegenerative disorders such as Alzheimer's and Parkinson's disease. Front Biosci 2008; 13: 492-504.

93 Quik M, McIntosh JM. Striatal alpha6* nicotinic acetylcholine receptors: potential targets for Parkinson's disease therapy. J Pharmacol Exp Ther 2006; 316: 481-9.

94 Ryan RE, Ross SA, Drago J, Loiacono RE. Dose-related neuroprotective effects of chronic nicotine in 6-hydroxydopamine treated rats, and loss of neuroprotection in alpha4 nicotinic receptor subunit knockout mice. Br J Pharmacol 2001; 132: 1650-6.

95 Perez XA, Bordia T, McIntosh JM, Grady SR, Quik M. Longterm nicotine treatment differentially regulates striatal alpha6alpha4beta2* and alpha6(nonalpha4)beta2* nAChR expression and function. Mol Pharmacol 2008; 74: 844-53.

96 Takeuchi H, Yanagida T, Inden M, Takata K, Kitamura Y, Yamakawa $\mathrm{K}$, et al. Nicotinic receptor stimulation protects nigral dopaminergic neurons in rotenone-induced Parkinson's disease models. J Neurosci Res 2009; 87: 576-85.

97 Xiao Y, Fan H. Musachio JL, Wei ZL, Chellappan SK, Kozikowski AP, et al. Sazetidine-A, a novel ligand that desensitizes alpha4beta2 nicotinic acetylcholine receptors without activating 
them. Mol Pharmacol 2006; 70: 1454-60.

98 Shytle RD, Mori T, Townsend K, Vendrame M, Sun N, Zeng J, et al. Cholinergic modulation of microglial activation by alpha 7 nicotinic receptors. J Neurochem 2004; 89: 337-43.

99 Khwaja M, McCormack A, McIntosh JM, Di Monte DA, Quik M. Nicotine partially protects against paraquat-induced nigrostriatal damage in mice; link to alpha6beta2* nAChRs. J Neurochem 2007; 100: 180-90.

100 Exley R, Cragg SJ. Presynaptic nicotinic receptors: a dynamic and diverse cholinergic filter of striatal dopamine neurotransmission. Br J Pharmacol 2008; 153 Suppl 1: S283-97.

101 Fedele E, Varnier G, Ansaldo MA, Raiteri M. Nicotine administration stimulates the in vivo $\mathrm{N}$-methyl-D-aspartate receptor/ nitric oxide/cyclic GMP pathway in rat hippocampus through glutamate release. Br J Pharmacol 1998; 125: 1042-8.

102 Garrido R, Mattson MP, Hennig B, Toborek M. Nicotine protects against arachidonic-acid-induced caspase activation, cytochrome $c$ release and apoptosis of cultured spinal cord neurons. J Neurochem 2001; 76: 1395-403.

103 Toborek M, Garrido R, Malecki A, Kaiser S, Mattson MP, Hennig B, et al. Nicotine attenuates arachidonic acid-induced overexpression of nitric oxide synthase in cultured spinal cord neurons. Exp Neurol 2000; 161: 609-20.

104 Mai H, May WS, Gao F, Jin Z, Deng X. A functional role for nicotine in $\mathrm{Bcl} 2$ phosphorylation and suppression of apoptosis. $\mathrm{J}$ Biol Chem 2003; 278: 1886-91.

105 Orr CF, Rowe DB, Halliday GM. An inflammatory review of Parkinson's disease. Prog Neurobiol 2002; 68: 325-40.

106 Roceri M, Molteni R, Fumagalli F, Racagni G, Gennarelli M, Corsini G, et al. Stimulatory role of dopamine on fibroblast growth factor-2 expression in rat striatum. J Neurochem 2001; 76: $990-7$.
107 Matarredona ER, Santiago M, Venero JL, Cano J, Machado A. Group II metabotropic glutamate receptor activation protects striatal dopaminergic nerve terminals against $\mathrm{MPP}^{+}$-induced neurotoxicity along with brain-derived neurotrophic factor induction. J Neurochem 2001; 76: 351-60.

108 Heininger K. A unifying hypothesis of Alzheimer's disease. IV. Causation and sequence of events. Rev Neurosci 2000; 11 Spec No: 213-28.

109 Selkoe DJ. Translating cell biology into therapeutic advances in Alzheimer's disease. Nature 1999; 399: A23-31.

110 Yankner BA. New clues to Alzheimer's disease: unraveling the roles of amyloid and tau. Nat Med 1996; 2: 850-2.

111 Almeida OP, Hulse GK, Lawrence D, Flicker L. Smoking as a risk factor for Alzheimer's disease: contrasting evidence from a systematic review of case-control and cohort studies. Addiction 2002; 97: 15-28.

112 Ott A, Slooter AJ, Hofman A, van Harskamp F, Witteman JC, Van Broeckhoven C, et al. Smoking and risk of dementia and Alzheimer's disease in a population-based cohort study: the Rotterdam Study. Lancet 1998; 351: 1840-3.

113 Utsuki T, Shoaib M, Holloway HW, Ingram DK, Wallace WC, Haroutunian V, et al. Nicotine lowers the secretion of the Alzheimer's amyloid beta-protein precursor that contains amyloid beta-peptide in rat. J Alzheimers Dis 2002; 4: 405-15.

114 Liu Q, Zhang J, Zhu H, Qin C, Chen Q, Zhao B. Dissecting the signaling pathway of nicotine-mediated neuroprotection in a mouse Alzheimer disease model. Faseb J 2007; 21: 61-73.

115 McFarlin DE, McFarland HF. Multiple sclerosis (first of two parts). N Engl J Med 1982; 307: 1183-8.

116 McFarlin DE, McFarland HF. Multiple sclerosis (second of two parts). N Engl J Med 1982; 307: 1246-51. 